\title{
Study of Vaginal Delivery Following Cesarean Section
}

\author{
Dr.P.Thilagavathi ${ }^{1}$ M.D ${ }^{1}$,Dr.V.Geetha ${ }^{2}$ M.D ${ }^{2}$. \\ ${ }^{I}$ Department of Obstetrics AndGynaecology, Coimbatore Medical College And Hospital/The Tamil Nadu Dr. \\ MGR Medical University, India \\ ${ }^{2}$ Department of Obstetrics AndGynaecology, Coimbatore Medical College And Hospital/The Tamil Nadu Dr. \\ MGR Medical University, India
}

\begin{abstract}
TOLAC (Trial of Labor after cesarean section) is an acceptable individualized option for women without major risk factors and the primary cesarean performed for a non recurring indication.

Objective: Aim of the study is to analyze the cases with history of previous cesarean section who delivered vaginally, the factors that influence the successful outcome, perinatal morbidity, mortality and finally maternal morbidity, mortality.

Materials and methods: 150 patients with the previous history of one caesarean section were studied.

Results: Among the 150 cases, 54 patients delivered vaginally and hence the incidence of vaginal birth after caesarean in the present study is 36\%. $72 \%$, who delivered vaginally belonged to the age group $21-30$. $75.93 \%$ of the women were second gravida with history of one previous section. Interval of time between previous caesarean section and the present pregnancy was $1-2$ years. It was also noticed that if a women had one or more full term normal deliveries before or after her last caesarean section, she stands a better chance of vaginal delivery again. Majority of babies weighed between $2.6-3 \mathrm{~kg}$.Conclusion: The patients with previous history of one cesarean section with no risk factors and average sized baby could be considered for vaginal delivery and to reduce the rate of unnecessary caesarean section.
\end{abstract}

Keywords: Cesearean section, Outlet forceps, perinatal morbidity, scar dehiscence, VBAC.

\section{Introduction}

The expectant attitude and individualization with respect to the management of pregnancy and labour in patient with previous caesarean section for non recurrent and even for recurrent indication are not only desirable but denote sound obstetric practice(sentilhes et al, 2013) .

\section{Aim Of The Study}

The aim of the studyis to analyze a large number of cases admitted with previous cesarean section who deliver vaginally. The factors that influence the successful outcome, perinatal morbidity, mortality and maternal morbidity, mortality are also analysed.This is to encourage women with history of previous caesarean section for vaginal delivery, in carefully selected cases and to reduce the rate of repeat section, complications and sequelae following the procedure.

\section{Materials And Methods}

The present study was undertaken from June 2015 to May 2016 in the department of Obstetrics and Gynaecology at Coimbatore medical college hospital, Coimbatore. One hundred and fifty cases of previous caesarean section were studied. In this series most of the patients had been operated previously in this hospital and only about $10 \%$ cases were operated elsewhere. Except $3 \%$ of cases, others were able to give correct data regarding their previous surgery.

The unbooked cases got admitted either early or late in labour. The booked cases were admitted around $38^{\text {th }}$ week. During each visit BP, \& weight were recorded, the height of the uterus, presentation noted and following investigation carried out.

1. Urine - for albumin, sugar, deposits

2. Haemoglobin estimation

3. Blood grouping and $\mathrm{RH}$ typing

4. Serum VDRL

5. Ultrasonography

Patients with complication like anemia, pregnancy induced hypertension were excluded from the study. Patients without complications were admitted 2 weeks before expected date of delivery for observation and evaluation as, to the type of delivery. In each case, a clinical assessment of pelvis was carried out after $38^{\text {th }}$ week of pregnancy. 
Patients with

1. Gynaecoid pelvis

2. Average size baby

3. Vertex presentation

4. No cephalopelvic disproportion

5. Lower segment transverse caesarean

6. History of previous uneventful post operative period.

7. Good uterine scarwere decided upon vaginal delivery.

During labour theatre personnel, anaesthetist, and pediatrician were alerted. Compatible blood was kept ready and sedation was given during first stage of labour. A close vigilance was maintained regarding maternal pulse, blood pressure, hydration and temperature. Cardiotocogram was used to monitor foetal heart rate and uterine contractions. Presence of scar tenderness and supra - pubic bulge was looked for. Finally, partograph was used to monitor the progress of labour.

Oxytocin for acceleration of labour was done in selected cases and carefully monitored. Forceps was usually applied to cut short second stage of labour. Routine scar exploration was not carried out in all patients following third stage of labour.

The condition of the baby like Apgar at 1 of $5 \mathrm{~min}$, weight, sex and type of delivery recorded. During the immediate post partum period and subsequent post natal follow up the condition of the mother and neonate were closely observed for detection of any complication and managed accordingly.

\section{Observation And Discussion}

Independent judgement is required for each previous caesarean pregnancy regarding its outcome. The management depends on, the indication of previous caesarean, type of incision, presentation and period of gestation.

Statistics for the year -2015

Coimbatore medical college hospital

Total number of deliveries in the year 2015 at CMCH $\quad$ - $\quad 7954$

Total number of caesarean sections $\quad$ - 1168

Total number of one previous caesarean cases $\quad-\quad 397$

Total number of 2 previous caesarean cases $\quad-\quad 21$

Total number of repeat caesarean section $\quad-\quad 326$

$\begin{array}{lll}\text { Number of vaginal birth after caesarean } & - & 92\end{array}$

Incidence of VBAC $\quad-\quad 22 \%$

The present study comprised of 150 cases, of previous caesarean section, planned to undergo trial of labour. Among the 150 cases, 54 patients delivered vaginally and the other 96 cases were taken up for repeat caesarean, due to various causes. The observation made from these 54 cases are depicted in different tables and analysis was done, considering several aspects.

The incidence of vaginal birth after caesarean in the present study is $36 \%$. The largest population based study reported a rate of 60.4 percent. The combined vaginal delivery rate for all prospective cohort studies, largely conducted in tertiary care centers and University settings, was 75.9 percent (2). A marked decline in VBAC occurred after the change in ACOG vaginal birth afterCesarean policy. Multiple factors have contributed to this decline, including patients refusing VBACafter counseling and inability of institutions to meet ACOG guidelines.

Also, the decline in VBAC rate and counselling the patient for VBAC was found to be influenced by the experience of consultant, previous involvement in the care of women with uterine rupture complicated by maternal or neonatal complications, and at the same time obstetrician'spreviousinvolvement in cesarean delivery related medical malpractice litigation.

Table no 1Age distribution of patients

\begin{tabular}{|l|l|l|}
\hline Age in years & No of cases & Percentage \\
\hline$<20$ & 13 & 24.0 \\
\hline $21-25$ & 23 & 42.5 \\
\hline $26-30$ & 16 & 29.6 \\
\hline$>31$ & 2 & 3.9 \\
\hline
\end{tabular}

From the above table, it is observed that majority of women $-72 \%$, who delivered vaginally belonged to the age group $21-30$. In Flamm et al (1990) also showed that the maximum number of cases were of age group $26-35$, which was comparable to our study. 
Table no - 2Distribution in relation to number of previous LSCS

\begin{tabular}{|l|l|l|}
\hline Prior LSCS & No of cases & Percentage \\
\hline 1 & 41 & 75.93 \\
\hline 2 & 13 & 24.07 \\
\hline
\end{tabular}

The above table shows that majority $75.93 \%$ of the women were second gravida with history of one previous sectionWhich was compareable to Flamm et al series.

Table no. 3Interval of time between last caesarean section and present pregnancy

\begin{tabular}{|l|l|l|}
\hline Time interval in years & No.of cases & Percentage \\
\hline $1-2$ & 29 & 53.8 \\
\hline $2-4$ & 22 & 40.7 \\
\hline $4-6$ & 3 & 5.5 \\
\hline$>6$ & - & - \\
\hline
\end{tabular}

In the majority of cases, interval of time between previous caesarean section and the present pregnancy was $1-2$ years.

Table no -4History of vaginal delivery prior and after caesarean section

\begin{tabular}{|l|l|l|l|}
\hline Vaginal delivery & Total no.cases & No. of VBAC & Percentage \\
\hline Before C.S. & 10 & 6 & $60 \%$ \\
\hline After C.S. & 5 & 4 & $80 \%$ \\
\hline Both & Nil & Nil & Nil \\
\hline
\end{tabular}

In the present study, 6 cases had history of vaginal birth before caesarean section, 4 cases had history of vaginal after caesarean section which was comparable to previous studies where Jhaveri's series, $(80.6 \%)$ delivered vaginally.V.K.Singh (1995) in his series reported $83.33 \%$ success rate in women who had history of vaginal delivery after caesarean section.This indicates that if a women had one or more full term normal deliveries before or after her last caesarean section, she stands a better chance of vaginal delivery again.

Table no - 5Indications of previous caesarean section

\begin{tabular}{|l|l|l|}
\hline Indications & No. Of Cases & Percentage \\
\hline Foetal Distress & 16 & 29.6 \\
\hline Malpresentation & 8 & 14.9 \\
\hline Post -Dated Pregnancy With Failed Induction & 5 & 9.2 \\
\hline Failure To Progress & 4 & 7.4 \\
\hline Cephalopelvic Disproportion & 3 & 5.5 \\
\hline Pregnancy Induced Hypertension/ Eclampsia & 1 & 1.9 \\
\hline Antepartum Haemorrhage & 1 & 1.9 \\
\hline Unknown & 16 & 29.6 \\
\hline
\end{tabular}

This table shows that there is no recurrent indication for repeat caesarean section.In the present study of 150 cases, $96(64 \%)$ of them underwent repeat caesarean section for foetal distress, threatened rupture, prolonged labour and failure to progress.Incidence of repeat caesarean section 64\% The reported incidence of repeat caesarean in selected women with previous caesarean pregnancy are as follows.

\begin{tabular}{|l|l|l|}
\hline Author & Year & Percentage \\
\hline Singh et al & 1995 & $34.16 \%$ \\
\hline Obara H et al & 1998 & $31 \%$ \\
\hline Stone C at al & 2000 & $68 \%$ \\
\hline Gregory et al & 2010 & $70 \%$ \\
\hline Studsgaard et al & 2013 & $67 \%$ \\
\hline Present Study & 2015 & $64 \%$ \\
\hline
\end{tabular}

Table No - 6Mode of vaginal Delivery

\begin{tabular}{|l|l|l|}
\hline Delivery & No of Cases & Percentage \\
\hline Labour Natural & 27 & $50 \%$ \\
\hline Outlet forceps & 27 & $50 \%$ \\
\hline
\end{tabular}

$50 \%$ of cases in our study delivered spontaneously, the remaining cases needed assistance in the form of outlet forceps. 
Table No - 7Duration of labour

\begin{tabular}{|l|l|l|}
\hline Duration of labour in hours & No. of cases & Percentage \\
\hline $0-2$ & 4 & 7.4 \\
\hline $2-4$ & 12 & 22.2 \\
\hline $4-6$ & 16 & 29.6 \\
\hline $6-8$ & 12 & 22.2 \\
\hline $8-10$ & 6 & 11.1 \\
\hline $10-12$ & 4 & 7.4 \\
\hline
\end{tabular}

In our study majority of cases were admitted in active labour and delivered within 8 hours.

In previous caesarean women with history of vaginal birth, the total duration of labour was $6.3 \pm 1.3 \mathrm{hrs}$, which was comparable with the study done by Guise et al., 2005 (2).

Table no: 8Foetal outcome

\begin{tabular}{|l|l|l|}
\hline Birth weight $(\mathrm{kg})$ & No of cases & Percentage \\
\hline$<2$ & - & - \\
\hline $2.1-2.5$ & 4 & 7.4 \\
\hline $2.6-3$ & 45 & 83.3 \\
\hline
\end{tabular}

Majority of babies weighed between $2.6-3 \mathrm{~kg}$, and maximum weight of the baby delivered vaginally in one study weighed $-3.4 \mathrm{~kg}$ Fetal weight was assessed clinically beforelabour and if evaluated more than 3.5 $\mathrm{kg}$ repeat caesarean was done.

Table no: 9Perinatal morbidity and mortality

\begin{tabular}{|l|l|l|}
\hline & No. of cases & Percentage \\
\hline Morbidity & 7 & 12.9 \\
\hline
\end{tabular}

In our study, morbidity was seen in 2 babies, one developed jaundice due to ABO incompatibility and the other baby was asphyxiated due to prolonged labour but both recovered

\begin{tabular}{|l|l|}
\hline Other studies & Incidence \% \\
\hline Martin & Nil \\
\hline Flamm & Nil \\
\hline Present Study & 1.8 \\
\hline
\end{tabular}

Table no: 10Maternal Morbidity

\begin{tabular}{|l|l|l|}
\hline morbidity & No of cases & Percentage \\
\hline Post PartumHaemorrhage (Atonic) & 1 & 1.8 \\
\hline Manual removal of placenta & 1 & 1.8 \\
\hline Scar dehiscence & 2 & 3.7 \\
\hline Sub total hysterectomy & 1 & 1.8 \\
\hline Scar rupture & Nil & - \\
\hline Rupture uterus & Nil & - \\
\hline
\end{tabular}

One of the cases had post partumhaemorrhage due to atonicity, and recovered completely with blood transfusion and other supportive measures like oxytocin and prostaglandins.

Two patients had scar dehiscence which was noticed intraoperatively when repeat caesarean was performedfor fetal distress.

Sub total hysterectomy was done for an unbooked case. The indication for previous caesarean was placenta praevia. After a short trial of labour, patient had fresh vaginal bleeding. On laparotomy there was a broad ligament haematoma and subtotal hysterectomy was done.

Scar rupture in the present study - Nil as compared to the previous studies where the incidence was reported as $0.2 \%(9)$ In our study, there was no maternal death.

\section{Summary And Conclusion}

150 cases of previous caesarean were given trial of labour of which 54 delivered vaginally. Hence the incidence of VBAC is $36 \%$. Majority of the cases in the study belonged to the age group of 21-30 years.

1. Among the 54 cases

Para1 - 75.93\% (41 cases)

Para $2 \quad-24.07 \%$ (13 cases)

2. The interval between the previous caesarean and present pregnancy was 2 yrs in $53.7 \%$.

3. $18.5 \%$ of the cases had a history of previous vaginal delivery. 
4. Indication for caesarean section in the previous pregnancy was not known in $29.6 \%$ and another $29.6 \%$ were operated for foetal distress.

5. $50 \%$ of the cases delivered spontaneously, outlet forceps used in another $46 \%$.

6. $51 \%$ of patients delivered within $4-8 \mathrm{hrs}$.

7. The average birth weight of foetus delivery vaginally was $2.6-3 \mathrm{~kg}$ in $83.3 \%$.

8. Perinatal mortality was $1.8 \%$, after excluding intra uterine deaths, prematurity and congenital anomalies.

9. Serious complication in the form of post-partum haemorrhage (1.8\%) and scar dehiscence(3.7\%) noticed. No rupture of uterus and no maternal deaths in this study.

10. $66.6 \%$ of them underwent puerperal sterilisation.

It decreases the duration of hospital stay and is cost effective.

\section{Conclusion}

To conclude, majority of the cases with previous caesarean section could be considered for vaginal delivery and to reduce the rate of unnecessary caesarean section. The old dictim" Once a caesarean always a caesarean" should be changed to "Once a caesarean always an institutional delivery".

The art of surgery may be necessary to perform what may be a difficult caesarean section, but to decide if this is necessary and to choose the ideal moment to deliver the child is definitely the art of obstetrics.In patients without any risk factors and history of a previous caesarean delivery, the risks of maternal and perinatal mortality and morbidity are similar between TOL and ERCD. Nevertheless TOL has a favorable benefit/riskbalance in most cases and its successreduces the risk of short and longtermmaternal complications.

\section{References}

[1]. Sentilhes L, Vayssiere C, Beucher G, Deneux-Tharaux C, Delivery for women with a previous cesarean: guidelines for clinical practice from the French college of Gynecologists and Obstetricians (CNGOF). Eur J ObstetGynecolReprod Biol. 2013, Sep 170(1):25-32

[2]. Guise JM, McDonagh MS, Hashima J, Kremer DF, Eden KB, Berlin M, Nygren P, Osterweil P, Krages KP and Helfand, Vaginal Birth After Cesarean (VBAC): Summary, AHHRQ Evidence Report summaries. Rockville (MD): Agency for HealthCare Research and Quality (US);1998-2005

[3]. JhaveriAA, Obstetric carrier after previous cesarean section, Journal of Obstetrics and Gynaecology, $1966-67$.

[4]. Singh V.K, Nawaui M, Bagoliwal, A, Rohatgi B, Trial of labour in patients with previous cesarean section, Journal of Obstetrics and Gynecology of India 1995.

[5]. Obara H, Minakami H, Koike T, Takamizawa S, Matsubar S, Sato I Vaginal birth after Cesarean Delivery : Results in 310 pregnancies, vol 24, April 1998, 129-134

[6]. Stone C, Halliday J, VBAC: a population study. PediatriperinatEpidemiol Oct 2000.

[7]. Flamm L.B, lawrence A, Newman, Stenan J Thomas, Debietallon, Michel M. Yoshida B.S., Vaginal birth after cesarean delivery, results of 5 years multicenter collaborative study, Obstetrics and gynecology, 1990, Vol 76,750

[8]. Martin JN, Morrison CJ, Wires WL, Vaginal birth after cesearean section, the demise of routine repeat abdominal delivery, 1988, 15 (4).

[9]. Beucher G, Dolley P, Levy-Thissier S, Florian A, Dreyfus M. Maternal benefits and risks of trial of labor versus elective repeat cesarean delivery in women with a previous cesarean delivery. J GynecolObstetBiolReprod 41(8):708-26 2012.

[10]. Gregory KD, Fridman M, Korst L. Trends and patterns of vaginal birth after cesarean availability in the United States SeminPerinatol 34(4):237-43,2010.

[11]. StudsgaardA, Skorstengaard M, Glavind J, Hvidman L, Uldbjerg N. Trial of labor compared to repeat cesarean section in women with no other risk factors than a prior cesarean delivery. ActaObsetGynecolScand, 92(11):1256-63, 2013 